\title{
LAJU EROSI TERHADAP PERUBAHAN TATA GUNA LAHAN KAWASAN HUTAN LINDUNG PADA AREA PERTANIAN DESA SUMBER BRANTAS, KECAMATAN BUMIAJI, KOTA BATU
}

\author{
Tatag Muttaqin, S.Hut, M.Sc. ${ }^{1}$ \\ Dosen Jurusan Kehutanan FPP-UMM
}

\begin{abstract}
Abstrak
Keberadaan produktifitas tanah semakin hari semakin menurun, hal ini disebabkan oleh laju erosi. Karakteristik lahan yang tidak sesuai peruntukannya juga akan mengakibatkan produktifitas lahan tersebut menjadi menurun. Peningkatan laju erosi dapat membuat sedimentasi pada sungai dan waduk semakin besar. Desa Sumber Brantas termasuk desa yang berada dalam kawasan rawan longsor, kekeringan dan banjir bandang. Penelitian ini bertujuan untuk mengidentifikasi nilai erosi pada lahan di Desa Sumber Brantas Kecamatan Bumiaji berdasarkan aplikasi WEPP serta untuk mengidentifikasi nilai klasifikasi kelas bahaya erosi yang ditimbulkan dari hasil pendugaan erosi dengan aplikasi WEPP.

Penelitian dilaksanakan di Desa Sumber Brantas Kecamatan Bumiaji Kota Batu pada bulan November 2016- Agustus 2017. Alat dan bahan yang digunakan untuk mendukung keberhasilan penelitian ini yaitu alat tulis, cetok, plastik, kertas label, kamera, clinometer, GPS, ArcGIS 9.3, WEPP versi 2012, dan, Microsoft Office. Pengambilan data di lapangan yang diperlukan sebagai data primer adalah data sampel tanah berupa tekstur tanah, kedalaman tanah, albedo, \% pasir, \% liat tanah, \% bahan organik, nilai Kapasitas Tukar Kation, \% batuan, dan albedo. Data sekunder berupa data curah hujan, topografi, jenis tanah dan penggunaan lahan.

Total nilai laju erosi yang terjadi pada Desa Sumber Brantas Kecamatan Bumiaji adalah sebanyak 657,700 ton/ha. Total nilai erosi tersebut berasal dari 364,715 ton/ha untuk lahan pertanian, sebanyak 8,898 ton/ha untuk lahan wanatani, sebanyak 283,200 ton/ha untuk pemukiman dan lahan hutan sebanyak 0,882 ton/ha. Total nilai erosi tanah yang terjadi di Desa Sumber Brantas Kecamatan Bumiaji adalah 657,700 ton/ha. Nilai erosi tersebut tergolong ke Kelas Bahaya Erosi V yaitu sangat berat.
\end{abstract}

\section{Kata kunci: Erosi, Perubahan tata guna lahan, Model WEPP}

\section{PENDAHULUAN}

Erosi tanah merupakan salah satu masalah lingkungan yang paling serius di seluruh belahan bumi saat ini, dan dalam jangka panjang adanya peningkatan erosi dan aliran permukaan dapat menyebabkan menurunnya kesuburan tanah di lahan yang terkena erosi (Sansakila, 2013).

Tata guna lahan yang salah dapat menyebabkan kenaikan laju erosi di suatu wilayah. Menurut Pratiwi (2013), bahwa karakteristik lahan yang sesuai peruntukannya juga akan mengakibatkan 
produktifitas lahan yang tersebut menjadi naik. Produktivitas lahan akan naik apabila karakteristik lahan digunakan dengan baik, sehingga menghasilkan hal-hal yang berguna untuk masyarakat.

Peningkatan laju erosi yang ada dapat membuat sedimentasi pada sungai atau waduk akan semakin besar. Peningkatan laju erosi ini juga bersamaan dengan peningkatan sedimentasi. Sedimentasi yang terjadi dapat berimbas pada daya guna waduk maupun keberadaan sungai berkurang. Secara tidak langsung juga sedimentsi yang ada dapat memicu banjir dan kekeringan

Peningkatan laju erosi yang ada dapat membuat sedimentasi pada sungai atau waduk akan semakin besar. Peningkatan laju erosi ini juga bersamaan dengan peningkatan sedimentasi. Sedimentasi yang terjadi dapat berimbas pada daya guna waduk maupun keberadaan sungai berkurang. Secara tidak langsung juga sedimentsi yang ada dapat memicu banjir dan kekeringan

Water Erosion Predict Project (WEPP) adalah aplikasi yang dapat digunakan untuk pendugaan nilai laju erosi tanah.Masukkan data untuk WEPP yaitu tanah, topografi, iklim dan penggunaan lahan. Keluaran seperti nilai erosi, sedimentasi dan run off membuat WEPP lebih unggul dari pendugaan erosi dengan metode lain.

Pemantauan yang diadakan secara berkelanjutan akan membuat membuat pengambilan kebijakan pengelolaan lingkungan juga berkelanjutan, sehingga diperlukan penelitian tentang laju erosi di berbagai lahan berdasarkan empat parameter antara lain: kelerengaan, tanah, iklim dan manajemen tanaman yang berada pada Kecamatan Bumiaji dapat menimbulkan dampak erosi.

Tujuan dari penelitian ini yaitu untuk mengidentifikasi nilai erosi pada lahan di Desa Sumber Brantas Kota Batu Kecamatan Bumiaji berdasarkan aplikasi
WEPP dan mengidentifikasi nilai klasifikasi kelas bahaya erosi yang ditimbulkan dari hasil pendugaan erosi dengan aplikasi WEPP

\section{METODE PENELITIAN}

\section{Waktu dan Tempat Penelitian}

Penelitian ini dilakukan pada bulan November 2016 hingga bulan November 2017 yang berada di Desa Sumber Brantas Kecamatan Bumiaji , Kota Batu, Provinsi Jawa Timur.

\section{Alat dan Bahan}

Alat dan bahan yang digunakan untuk mendukung keberhasilan penelitian ini yaitu alat tulis, cetok, plastik, kertas label, kamera, clinometer, GPS, ArcGIS 9.3, WEPP versi 2012, dan, Microsoft Office.

\section{Metode Pengambilan Data}

Metode pengambilan data Dalam penelitian pengambilan data di lapangan yang diperlukan sebagai data primer adalah data contoh tanah, topografi dan penggunaan lahan. Data contoh tanah berupa tekstur tanah, kedalaman tanah, \% pasir, \% liat tanah, \% bahan organik, nilai Kapasitas Tukar Kation, \% batuan, dan albedo. Data topografi berupa panjang lereng $(\mathrm{m})$ dan kemiringan lahan (\%). Data penggunaan lahan langsung mencatat penggunaan lahan di lapangan. Data sekunder yang digunakan ialah data iklim yang diperlukan adalah data temperatur maksimum dan minimum, curah hujan, letak geografis dan elevasi stasiun hujan

\section{Metode Analisis Data}

1. Install program WEPP versi 2012, selanjutnya pilih use the default WEPP project untuk memulai pendugaan erosi secara langsung

2. Tampilan umum program yang memperlihatkan kondisi lahan secara melintang serta saling 
bertumpukan. Tumpukan tersebut terdiri atas jenis tanah, penggunaan lahan dan kemiringan lahan.

3. Data klimatologi yang telah didapat dibuat dalam format text dengan cara memasukannya ke format text (notepad). Data klimatologi ini berupa data curah hujan, temperatur maksimum dan minimum terlebih dahulu.

4. Langkah-langkah selanjutnya sebagai berikut :

$>$ WEPP Tools - Add Climates

$>$ Pemberian nama stasiun hujan baru daerah penelitian $>$ Next

$>$ Pemilihan lokasi stasiun hujan Amerika yang tersedia tersedia, memilih yang hampir sesuai dengan stasiun hujan lokasi penelitian $>$ Next

$>$ Selanjutnya akan mucul pertanyaan untuk membuat data .par > Yes > Next, kemudian memasukan data klimatologi aktual dengan format text untuk membuat file .par > Next

$>$ Pada lembar kerja kemudian memilih refresh data view sehingga data aktual akan ditampilkan dan mengubah parameter sesuai dengan satuan yang digunakan pada data aktual > Next

$>$ Mengoreksi data setiap parameter iklim yang tertera pada masing masing kolom dengan data primer yang diperoleh $>$ Next

$>$ Membangun input iklim dengan CLIGEN versi $4.3>$ Finish.

5. Selanjutnya membentuk stasiun hujan baru dengan menggunakan data lapangan untuk mendapatkan komponen iklim, kemudian memasukkan komponen manajemen tanaman sesuai dengan tipe penggunaan lahan.

6. Memasukan data kelerengan dan panjang lereng sesuai dengan data lapangan setiap segment.
7. Memasukan data tanah yang ada di lapangan ialah komponen terakhir yang diperlukan untuk memperoleh hasil pengamatan aktual.

\section{HASIL DAN PEMBAHASAN}

\section{Hasil Pengamatan}

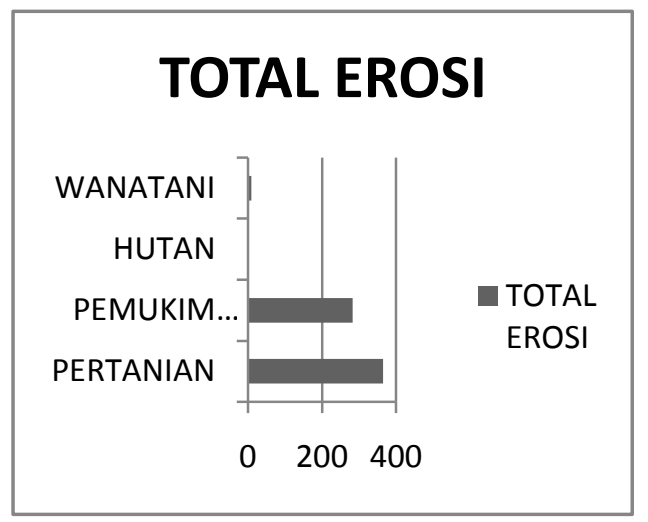

\section{Gambar 1. Total Erosi di Lokasi Penelitian}

Hasil dari pendugaan erosi ini ditunjukkan dari hasil pendugaan erosi WEPP sebesar 364,715 ton/ha/tahun untuk lahan pertanian, sebesar 8,898 ton/ha/tahun untuk lahan wanatani, sebesar 283,200 ton/ha/tahun untuk pemukiman dan lahan hutan sebesar 0,882 ton/ha/tahun. Total dari 5 jenis tanah tersebut nantinya akan dijumlahkan, sehingga akan memunculkan jumlah nilai erosi yang terjadi di Kecamatan Bumiaji yaitu sebesar 657,700 ton/ha/tahun.

Lahan pertanian ini memiliki tanaman seperti bawang merah, kubis, dan bawang prei. Tanaman-tanaman tersebut memiliki jarak yang tidak terlalu jauh dari tanah. Jarak rendah tersebut membuat pukulan air hujan akan menyentuh tanah dengan keras. Hal tersebut membuat erosi percikan terjadi yang lama-lam akan menjadi alur, sehingga akan membuat nilai laju erosi yang besar yaitu 362,175 ton/ha/tahun. 
Lahan hutan ini ditanami Pinus (Pinus merkusii) dan Eucaliptus degulpta kedua tanaman ini sering dijumpai di beberapa lahan hutan. Pohon ini memiliki kemampuan menahan pukulan air hujan ke tanah. Ranting-ranting dan dedaunan akan membuat air hujan turun dengan perlahan ke tanah. Sehingga nilai erosi yang dihasilkan kecil yaitu sekitar 0,882 ton/ha/tahun.

Lahan pemukiman adalah lahan yang dimanfaatkan oleh manusia untuk bertempat tinggal. Pada umumnya di perkarangan tidak memiliki pohon atau perkarangannya disemen sehingga air hujan akan langsung jatuh ke tanah, sehingga menyebabkan erosi yang tinggi di lahan pemukiman yaitu 283,200 ton/ha/tahun.

Lahan wanatani adalah lahan yang diduga kerjasama antara perhutani dan masyarakat. Lahan wanatani ditanami tanaman tahunan yaitu Eucaliptus deglupta dan tanaman musiman yaitu bawang prei. Lahan ini memiliki nilai erosi yang lebih rendah dari lahan pertanian yaitu 8,898 ton/ha/tahun. Hal tersebut diduga karena adanya pohon Eucalpitus deglupta dapat menahan air hujan dengan daun ataupun ranting.

Tabe1. I Klasifikasi Kelas Bahaya Erosi

\begin{tabular}{|l|l|l|}
\hline Kelas bahaya Erosi & Laju Erosi (ton/ha/tahun) & Keterangan \\
\hline I & $<15$ & Sangat Ringan \\
\hline II & $15-60$ & Ringan \\
\hline III & $60-180$ & Sedang \\
\hline IV & $180-480$ & Berat \\
\hline V & $>480$ & Sangat Berat \\
\hline
\end{tabular}

Sumber: Suripin (2004)

Menurut tabel klasifikasi Kelas Bahaya Erosi (Suripin, 2004) terbagi menjadi 5 kelas, yaitu kelas I, II, III, IV dan V. Setiap kelas memiliki besar erosi masing-masing, sehingga nantinya dapat disesuaikan dengan tabel klasifikasi Kelas Bahaya Erosi. Keberadaan nilai besaran erosi yang ada tersebut akan dapat disesuaikan untuk nilai erosi yang telah terjadi di Kecamatan Bumiaji, sehingga apabila disesuaikan, menjadi klasifikasi Kelas Bahaya Erosi Kecamatan Bumiaji termasuk kedalam kelas V. Kelas tersebut menunjukkan bahwa erosi yang telah terjadi di Kecamatan Bumiaji termasuk kedalam kategori yang sangat berat.

\section{Pembahasan}

\section{Menurut Pratiwi}

(2013) menyatakan bahwa besarnya curah hujan, intensitas, dan kecepatan jatuhnya hujan menentukan kekuatan penghancuran agregat-agregat tanah, jumlah, dan kekuatan limpasan permukaan. Intensitas hujan yang ada di Kecamatan Bumiaji tergolong intenstas hujan yang rendah. Menurut klasifikasi intensitas hujan (Arsyad, 2012) menyatakan bahwa intensitas hujan di Kecamatan Bumiaji tergolong intensitas yang rendah. Intensitas hujan yang rendah masih mampu menghasilkan nilai laju erosi seberat 657,700 ton/ha/tahun. Hal tersebut menunjukkan bahwa nilai laju erosi sulit mencapai titik terendah (nol), walaupun manusia berusaha untuk menekan nilai laju erosi tersebut. 


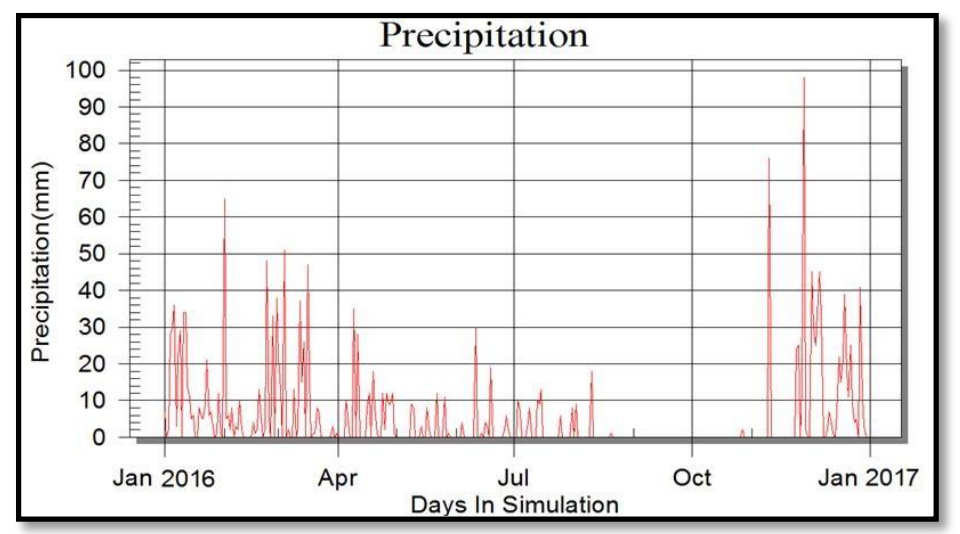

\section{Gambar 1. Grafik curah hujan harian tahun 2016 di Lokasi Penelitian}

Topografi di Kecamatan Bumiaji bervariasi dengan panjang lereng dan kemiringan lahan yang berbeda. Panjang lereng ataupun kemiringan lahan yang curam membuat nilai erosi yang besar pula. Faktor topografi membuat air limpasan membawa lapisan tanah. Kemiringan lahan yang besar membuat air limpasan semakin banyak membawa lapisan tanah dan panjang lereng menambah besar nilai laju erosi. Panjang lereng yang besar akan membuat air limpasan semakin banyak membawa lapisan tanah. Hal tersebut sesuai dengan pernyataan Dewi, Ni Made, Tatiek (2012), panjang lereng berperan terhadap besarnya erosi yang terjadi, semakin panjang lereng maka semakin besar volume aliran permukaan yang terjadi. Kemiringan lereng memberikan pengaruh besar terhadap erosi yang terjadi, karena sangat mempengaruhi kecepatan limpasan permukaan. Makin besar nilai kemiringan lereng, maka kesempatan air untuk masuk kedalam tanah (infiltrasi) akan terhambat sehingga volume limpasan permukaan semakin besar yang mengakibatkan terjadinya bahaya erosi.

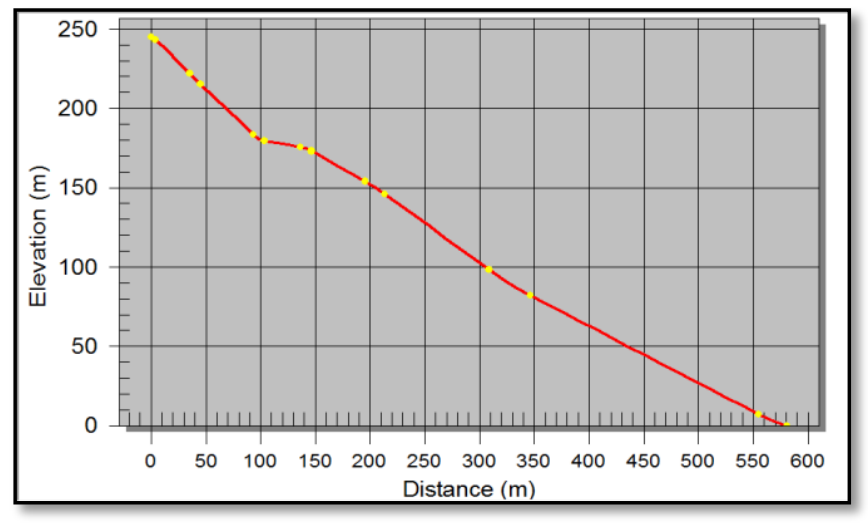

\section{Gambar 2 . Grafik kelerengan pada lokasi penelitian}

Menurut Pratiwi (2013) menyatakan bahwa vegetasi penutup lahan memegang peranan penting dalam proses intersepsi hujan yang jatuh dan transpirasi air yang terabsorpsi oleh akar. Lahan dengan penutupan yang baik memiliki kemampuan meredam energi kinetik hujan, sehingga memperkecil terjadinya erosi 
percik, memperkecil koefisien aliran sehingga mempertinggi kemungkinan penyerapan air hujan, khususnya pada lahan yang memiliki solum tebal.

Erodibilitas atau kepekaan tanah adalah kemampuan tanah untuk mengalami erosi. Nilai erodibilitas tanah sangat dipengaruhi data struktur tanah, bahan organik, tekstur, dan permeabilitas tanah (Segel dan Putuhena, 2005). Bahan organik ini didapatkan dari ranting ataupun daun tanaman. Tekstur tanah yang berupa liat dan pasir membuat nilai laju erosi timbul. Permeabilitas tanah mempengaruhi besar kecilnya erosi, air hujan yang sulit masuk ke tanah membuat nilai laju erosi besar. Erodibilitas tanah, atau faktor kepekaan erosi tanah, yang merupakan daya tahan tanah baik terhadap penglepasan dan pengangkutan, terutama tergantung pada sifat-sifat tanah, seperti tekstur, stabilitas agregat, kekuatan geser, kapasitas infiltrasi, kandungan bahan organik dan kimiawi juga tergantung pada posisi topografi, kemiringan lereng dan gangguan oleh manusia (Suripin, 2002).

Penggunaan lahan akan tepat guna jika lahan tersebut digunakan sesuai dengan kemampuan alami yang dimilikinya. Kemampuan itu ditentukan oleh sifat dan ciri lahan itu sendiri. Pengelolaan dan pemanfaatan yang salah dapat menimbulkan kerusakan lahan. Penggunaan lahan digunakan sebagai strategi pengendalian erosi yang memperhatikan faktor penutupan lahan sebagai pelindung dari penghancuran butir-butir hujan, meningkatkan kapasitas infiltrasi tanah untuk mengurangi aliran permukaan, memperbaiki atau meningkatkan stabilitas agregat tanah, dan meningkatkan kekasaran permukaan untuk mengurangi kecepatan aliran permukaan dan angin (Pratiwi, 2013). Lahan yang ada akan dapat dimanfaatkan secara optimal untuk kehidupan masyarakat tanpa menimbukan dampak negatif seperti tanah longsor dan banjir.

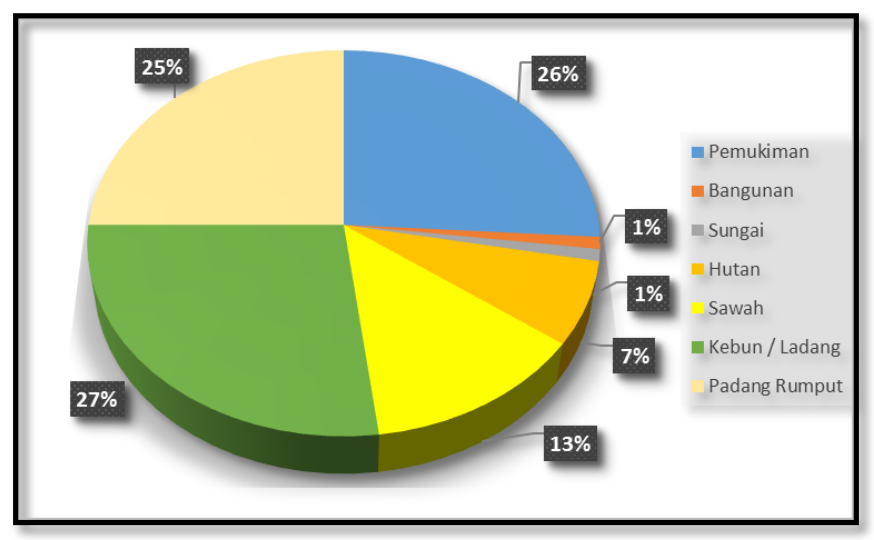

Gambar 3 . Diagram penggunaan lahan di kecamatan Bumiaji

\section{KESIMPULAN}

Dari penelitian yang telah dilakukan dapat disimpulkan bahwa:

1) Total nilai laju erosi tanah yang terjadi pada Desa Sumber Brantas Kecamatan Bumiaji adalah sebanyak 657,700 ton/ha/tahun. Total nilai erosi tersebut berasal dari 364,715 ton/ha/tahun untuk lahan pertanian, sebanyak 8,898 ton/ha/tahun untuk lahan wanatani, sebanyak 283,200 ton/ha /tahun untuk pemukiman dan sebanyak 0,882 ton/ha/tahun untuk lahan hutan.

2) Total nilai laju erosi tanah yang terjadi di Desa Sumber Brantas Kecamatan 
Bumiaji adalah 657,700 ton/ha/tahun. Nilai laju erosi tersebut tergolong ke Kelas Bahaya Erosi V yaitu sangat berat.

\section{DAFTAR PUSTAKA}

Arsyad,S. 2012. Konservasi Tanah dan Air. Institut Pertanian Bogor Press: Bogor.

Dewi, I. G. A. S. U., Ni Made, T., Tatiek K. 2012. Prediksi Erosi dan Perencanaan Konservasi Tanah dan Air pada Daerah Aliran Sungai Saba. Jurnal Agroekoteknologi Tropika ISSN: 2301-6515 Vol. 1, No. 1.

Pratiwi, V. 2013. Aplikasi Model WEPP untuk Pendugaan Erosi di Sub Daerah Aliran Sungai Tinalah . Skripsi tidak diterbtkan. Fakultas Kehutanan Universitas Gadjah Mada: Yogyakarta

Segel, H. G. dan Putuhena, W.M. 2005. Estimasi Erosi Lahan di Daerah Aliran Danau Tondano Menggunakan Geographic Information System (GIS). Jurnal Sumber Daya Alam Vol. 1, No. 1: hal. 65-69.

Sansakila, S., F. 2015. Analisis Laju Erosi pada Area Pertanian terhadap Perubahan Tata Guna Lahan di Kawasan Hutan Lindung Desa Sumber Brantas, Kecamatan Bumiaji, Kota Batu. Skripsi tidak diterbitkan. Jurusan Kehutanan Fakultas Pertanian Dan Peternakan Universitas Muhammadiyah Malang: Malang.

Pratiwi, V. 2013. Aplikasi Model WEPP untuk Pendugaan Erosi di Sub Daerah Aliran Sungai Tinalah. Skripsi tidak diterbtkan. Fakultas
Kehutanan Universitas Gadjah Mada: Yogyakarta

Suripin. 2002. Pengelolaan Sumber Daya Tanah dan Air. Andi offset: Yogyakarta.

Suripin. 2004. Sistem Drainse Perkotaan yang Berkelanjutan. Andi offset: Yogyakarta. 